\title{
The Relationship between Secondary Structure and Biodegradation Behavior of Silk Fibroin Scaffolds
}

\author{
Yongpei Hu, Qin Zhang, Renchuan You, Lingshuang Wang, and Mingzhong Li \\ National Engineering Laboratory for Modern Silk, College of Textile and Clothing Engineering, Soochow University, \\ No. 199 Ren'ai Road, Industrial Park, Suzhou 215123, China \\ Correspondence should be addressed to Mingzhong Li, mzli@suda.edu.cn
}

Received 6 June 2012; Accepted 16 July 2012

Academic Editor: Amit Bandyopadhyay

Copyright (c) 2012 Yongpei Hu et al. This is an open access article distributed under the Creative Commons Attribution License, which permits unrestricted use, distribution, and reproduction in any medium, provided the original work is properly cited.

\begin{abstract}
Silk fibroin has a unique and useful combination of properties, including good biocompatibility and excellent mechanical performance. These features provided early clues to the utility of regenerated silk fibroin as a scaffold/matrix for tissue engineering. The silk fibroin scaffolds used for tissue engineering should degrade at a rate that matches the tissue growth rate. The relationship between secondary structure and biodegradation behavior of silk fibroin scaffolds was investigated in this study. Scaffolds with different secondary structure were prepared by controlling the freezing temperature and by treatment with carbodiimide or ethanol. The quantitative proportions of each secondary structure were obtained by Fourier transform infrared spectroscopy (FTIR), and each sample was then degraded in vitro with collagenase IA for 18 days. The results show that a high content of $\beta$ sheet structure leads to a low degradation rate. The random coil region in the silk fibroin material is degraded, whereas the crystal region remains stable and the amount of $\beta$-sheet structure increases during incubation. The results demonstrate that it is possible to control the degradation rate of a silk fibroin scaffold by controlling the content of $\beta$-sheet structure.
\end{abstract}

\section{Introduction}

Silk fibroin is a natural protein produced by the domestic silkworm Bombyx mori, which is composed of a heavy-chain (H-chain, $350 \mathrm{kDa}$ ), light-chain (L-chain, $25 \mathrm{kDa}$ ), and an accessory protein $(30 \mathrm{kDa})$. The amino acid composition of silk fibroin from Bombyx mori consists primarily of glycine, alanine, and serine $[1,2]$. The three simple amino acids form the crystalline regions of silk fibroin, while the amino acids with bulky and polar side chains form the amorphous regions [3]. The silk polymorphs include silk I, silk II, and an air/water assembled interfacial silk III $[1,4]$. The molecular conformation of silk II is antiparallel $\beta$-sheet structure.

Silk fibroin has been used for centuries in production of textiles and clinical sutures [5]. Silk fibroin materials can support the attachment, proliferation, and differentiation of primary cells and cell lines [6-8] and is easily prepared as films [9], porous scaffolds [10], gels [11], and mats [12]. The impressive cytocompatibility and malleability of SF materials make silk a popular starting material for tissue engineering scaffolds used in skin, bone, blood vessel, ligament, and nerve tissue regeneration [13-15].

An ideal tissue engineering scaffold is nonimmunogenic and nontoxic but is biocompatible and supports cell adhesion, proliferation, and differentiation. In particular, the material should be biodegradable in vivo and degradation products should be nontoxic and easily cleared from the body [16]. It is important that scaffolds used for tissue engineering should degrade at a rate that matches the rate of tissue growth [17]. Recently, based on the importance of degradation for biomaterial applications in tissue engineering, the degradation behavior of silk fibroin materials has been well studied $[3,10,18,19]$. The rate and extent of degradation may be highly variable, depending on a series of factors related to the properties of scaffolds, processing conditions, as well as the chemical and biochemical environment of the site of implantation [20]. These results highlight that silk fibroin biomaterials are biodegradable, and the degradation behaviors could be regulated. However, how to control the degradation rate of silk fibroin material is not clear. 
Here, scaffolds with different secondary structures were prepared by controlling the freezing temperature and by treatment with carbodiimide (EDC) or ethanol. The relationship between secondary structure and enzymatic biodegradation behavior of silk fibroin scaffolds was investigated in the present study. It will become more predictable to control the degradability of silk-based materials according to the requirements of various tissue regenerations.

\section{Materials and Methods}

2.1. Preparation of Silk Fibroin Aqueous Solution. Raw B. mori silk consists of two kinds of proteins, fibroin and sericin. To remove sericin, silk was treated three times with 0.05 (wt \%) $\mathrm{Na}_{2} \mathrm{CO}_{3}$ for $30 \mathrm{~min}$ at $98-100^{\circ} \mathrm{C}$. The pure fibroin fibers were dissolved in $\mathrm{CaCl}_{2} / \mathrm{CH}_{3} \mathrm{CH}_{2} \mathrm{OH} / \mathrm{H}_{2} \mathrm{O}$ (molar ratio $1: 2: 8$ ) at $72 \pm 2{ }^{\circ} \mathrm{C}$ with stirring. The solution was filtered and dialyzed against distilled water for 4 days to obtain a solution of silk fibroin.

2.2. Preparation of Silk Fibroin Scaffolds. Four groups of porous silk fibroin scaffolds were prepared. Group A: a sample of $3(\mathrm{wt} \%)$ silk fibroin solution was placed into metal vessels $(\sim 2 \mathrm{~mm})$ and frozen at $-7^{\circ} \mathrm{C}$ for $>5$ days then dried in a freeze-dryer (Genesis 25-LE, Virtis) for $48 \mathrm{~h}$. Group B: an aliquot of ethyl oxide ester was added as a cross-linking agent to a $3(\mathrm{wt} \%)$ silk fibroin solution and stirred slowly for $2 \mathrm{~h}$ at $70^{\circ} \mathrm{C}$. After vacuum defoaming, the silk fibroin solution was frozen at $-40^{\circ} \mathrm{C}$ for $6 \mathrm{~h}$ then freeze-dried for $48 \mathrm{~h}$. Group C: group B material was kept at room temperature for $>1$ day then immersed in EDC/NHS/MES (1-ethyl-3-(3dimethylaminopropyl) carbodiimide hydrochloride/N-hydroxysuccinimide/2-morpholinoethanesulfonic acid, 40/20/ $50 \mathrm{mM}$ ) for $24 \mathrm{~h}$. The silk fibroin was taken out and immersed in distilled water for $24 \mathrm{~h}$ then freeze-dried again for $48 \mathrm{~h}$. Group D: group B material was kept at room temperature for $>1$ day then soaked in $75 \%$ ethanol for $2 \mathrm{~h}$. The silk fibroin was taken out and immersed in distilled water for $24 \mathrm{~h}$ then freeze-dried for $48 \mathrm{~h}$.

2.3. The Silk Fibroin Scaffolds In Vitro Degradation. Silk fibroin scaffold from each group was cut into $3 \mathrm{~cm} \times$ $3 \mathrm{~cm}$ squares and weighed. The fibroin squares were then immersed in $0.05 \mathrm{M}$ PBS ( $\mathrm{pH} 7.0$ ) at $37^{\circ} \mathrm{C}$ for $48 \mathrm{~h}$ to eliminate non-crosslinked silk fibroin. A portion of the samples was dried at $105^{\circ} \mathrm{C}$ to calculate the weight of samples as initial mass. Each fibroin square was incubated in $1.0 \mathrm{U} / \mathrm{mL}$ collagenase IA (Sigma, USA) dissolved in $0.05 \mathrm{M}$ PBS (pH 7.0) at $37^{\circ} \mathrm{C}$. After $1,3,6,12$, and 18 days, at least three of the fibroin squares were removed, and the enzyme containing the degradation products was replaced with freshly prepared enzyme solution. Samples were immersed in 0.05 M PBS (no enzyme) as controls.

2.4. Scanning Electron Microscopy (SEM). The appearance of samples after degradation with collagenase IA for different lengths of time was examined with a Hitachi S-570 scanning electron microscope.

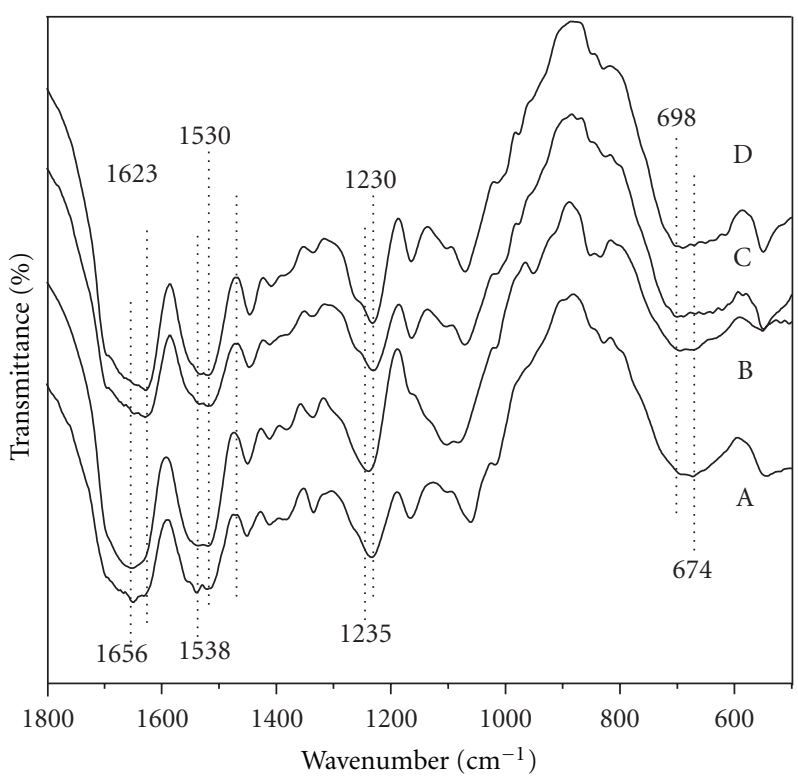

FIGURE 1: FTIR spectra of four groups of silk fibroin scaffold before degradation.

2.5. Fourier Transform Infrared Spectroscopy (FTIR). FTIR spectra of the nondegradable scaffolds and the freeze-dried products after degradation were obtained with a Nicolet Avatar-IR 360 spectrometer. From 1595 to $1720 \mathrm{~cm}^{-1}$ of the amide I spectrum was selected to make the $\mathrm{AB}$ transformation and baseline modulation with OPUS 6.5 software, then peak-differentiation imitated with PeakFit v4.12 software to obtain the percentage composition of different secondary structures in the silk fibroin material.

2.6. Amino Acid Analysis. After degradation with collagenase IA, the residual fibroin scaffolds were hydrolyzed in $6 \mathrm{M} \mathrm{HCl}$ at $110^{\circ} \mathrm{C}$ for $18 \mathrm{~h}$. An amino acid analyzer (Hitachi model 835-50) was used to determine the identity and quantity of amino acids in the hydrolyzed products. The degradation products of the silk fibroin scaffold were applied directly (without hydrolysis) to an amino acid analyzer to determine the free amino acids.

\section{Results and Discussion}

3.1. Secondary Structure of Fibroin Scaffold. Figure 1 shows the situation before degradation. Group A (curve A) is characterized by absorption bands at $\sim 1656 \mathrm{~cm}^{-1}$ (amide I), $\sim 1538 \mathrm{~cm}^{-1}$ (amide II), $\sim 1232 \mathrm{~cm}^{-1}$ (amide III), and $\sim$ $674 \mathrm{~cm}^{-1}$ (amide V), indicating that the secondary structure of the scaffold is mainly random coil and $\alpha$-helix; the percentage composition of calculated $\beta$-sheet is $25.65 \%$ (Table 1) with similar peak-differentiation which shows that before degradation. Group B (curve B) is characterized by absorption bands at $\sim 1650 \mathrm{~cm}^{-1}$ (amide I), $\sim 1540 \mathrm{~cm}^{-1}$ (amide II), $\sim 1235 \mathrm{~cm}^{-1}$ (amide III), and $\sim 669 \mathrm{~cm}^{-1}$ (amide $\mathrm{V})$, indicating that the secondary structure of the scaffold is mainly random coil and $\alpha$-helix; the quantitative proportion 
TABLE 1: Relative content of secondary structure of four groups of silk fibroin scaffolds before degradation (\%).

\begin{tabular}{lcccc}
\hline Groups & A & B & C & D \\
\hline Side chain & 3.79 & 3.44 & 4.69 & 5.35 \\
$\beta$-sheet & 25.65 & 28.34 & 34.30 & 39.94 \\
Random coil & 18.28 & 22.67 & 21.15 & 18.15 \\
$\alpha$-form & 17.56 & 10.37 & 10.54 & 9.45 \\
Turns & 34.72 & 35.18 & 29.33 & 27.11 \\
\hline
\end{tabular}

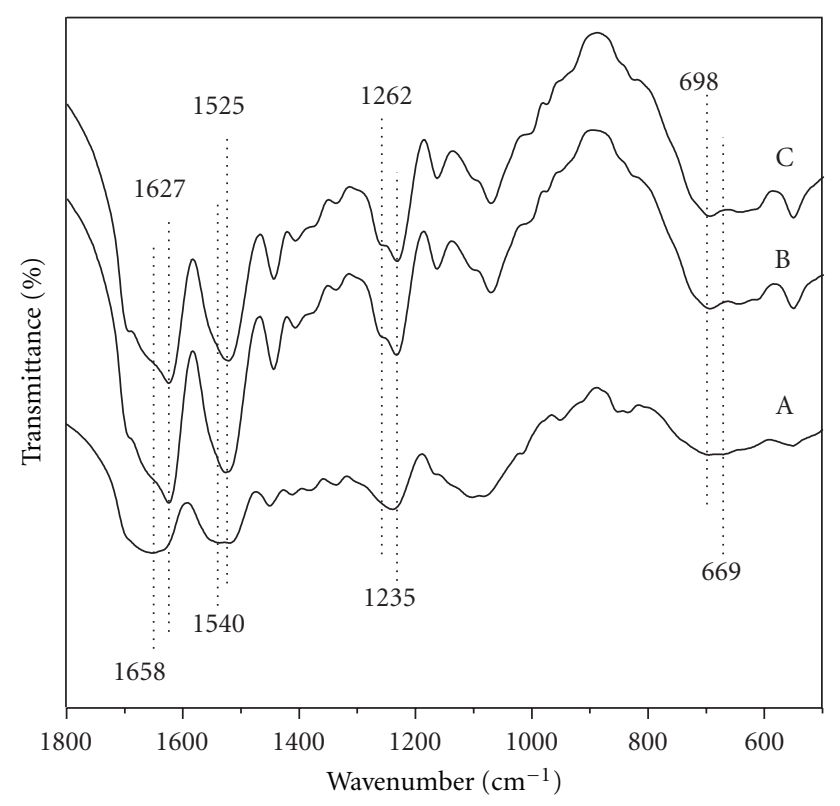

FIGURE 2: FTIR spectra of group B of porous silk fibroin scaffold incubated with collagenase IA for A, 0 day; B, 6 days; C, 18 days.

of $\beta$-sheet is $28.34 \%$. Group C (curve C) is characterized by absorption bands at $\sim 1627 \mathrm{~cm}^{-1}$ (amide I), $\sim 1525 \mathrm{~cm}^{-1}$ (amide II), $\sim 1230 \mathrm{~cm}^{-1}$ (amide III), and $\sim 700 \mathrm{~cm}^{-1}$ (amide $\mathrm{V}$ ), which indicates the content of $\beta$-sheet is high ( 34.30\%). Group D (curve D) is characterized by absorption bands at $\sim 1623 \mathrm{~cm}^{-1}$ (amide I), $\sim 1530 \mathrm{~cm}^{-1}$ (amide II), $\sim 1230 \mathrm{~cm}^{-1}$ (amide III), and $\sim 700 \mathrm{~cm}^{-1}$ (amide V), indicating the content of $\beta$-sheet is highest in this group $(\sim 39.94 \%)$. The content of $\beta$-sheet is in the order $\mathrm{D}>\mathrm{C}$ $>\mathrm{B}>\mathrm{A}$ as determined through qualitative analysis and quantitative calculation of the FTIR spectrum of four groups of porous silk fibroin scaffolds.

3.2. Structure Changes in Silk Fibroin Scaffold during Enzymatic Degradation. Figure 2 curves B and C show that, after collagenase IA-induced degradation of group B scaffold, absorption bands at $1627 \mathrm{~cm}^{-1}$ (amide I), $1525 \mathrm{~cm}^{-1}$ (amide II) and $698 \mathrm{~cm}^{-1}$ (amide V) appeared in the FTIR spectrum. According to Table 2, group B was degraded after 6 days, during which time the content of random coil decreased from 22.67 to $20.99 \%$ and the content of $\beta$-sheet increased from 28.34 to $34.57 \%$. After 18 days, the content of random
TABLE 2: Relative content of secondary structure of group B porous silk fibroin scaffold during degradation (\%).

\begin{tabular}{lccc}
\hline Degradation time/day & $0 \mathrm{~d}$ & $6 \mathrm{~d}$ & $18 \mathrm{~d}$ \\
\hline Side chain & 3.44 & 4.77 & 6.08 \\
$\beta$-sheet & 28.34 & 34.57 & 39.26 \\
Random coil & 22.67 & 20.99 & 16.90 \\
$\alpha$-form & 10.37 & 9.80 & 9.40 \\
Turns & 35.18 & 29.87 & 28.35 \\
\hline
\end{tabular}

coil was reduced to $16.90 \%$, whereas the content of $\beta$-sheet was increased to $39.26 \%$ in the residual fibroin scaffolds. These results indicate that collagenase IA is more aggressive toward the random coil region than the $\beta$-sheet structure region of fibroin. The $\beta$-sheet structure region of silk fibroin, according to the macromolecular chains arrangement rule, is highly resistant to protease attack.

3.3. Amino Acid Analysis of Silk Fibroin Degradation Products. With degradation by collagenase IA for increasing lengths of time, the amounts of Asp, Thr, Ile, Leu, Phe, Arg, and Pro in residual fibroin scaffold are low, and there are large quantities of free amino acids (Tyr, Phe, Gly, Ser, Thr, Ala,Val, and Lys) in the degradation products from silk fibroin scaffolds. These free amino acids were found mainly in the random coil region of silk fibroin, further illustrating the priority of collagenase IA to attack the region of random coil structure of silk fibroin materials and the ability of the $\beta$ sheet structure region to resist enzymatic degradation. This confirms that collagenase IA has powerful ability to degrade silk fibroin, which can be hydrolyzed to free amino acids.

3.4. Morphologic Changes. The degradation of each group of silk fibroin material for different lengths of time with collagenase IA after was examined by SEM (Figure 3). Groups A and B silk fibroin could not retain the original form and collapsed after 6 days with total loss of the pore structure. Group C fibroin scaffold collapsed partially, and the difference is more marked after 18 days. The internal pores in the groups A-C silk fibroin scaffolds of all collapsed and to the most serious degree in group A. By contrast, the pore structure remained regular in the group D fibroin scaffold. The results obtained by SEM showed that the high content of $\beta$-sheet structure was associated with a low degradation rate.

3.5. Mass Loss. The content of $\beta$-sheet in the four groups decreases in the order D $>C>B>A$. Figure 4 shows the mass of the four groups of silk fibroin scaffolds is reduced by collagenase IA-induced degradation after 1 day but the difference is not significant. The difference of mass loss between the four groups increased gradually in the next 17 days. After 18 days, the mass of group D silk fibroin scaffold was reduced by only $7.59 \%$, whereas the mass of group B silk fibroin scaffold without treatment with ethanol was reduced by $50.42 \%$. The mass of the group B fibroin is much larger than that of group $\mathrm{D}$, indicating that the content of 

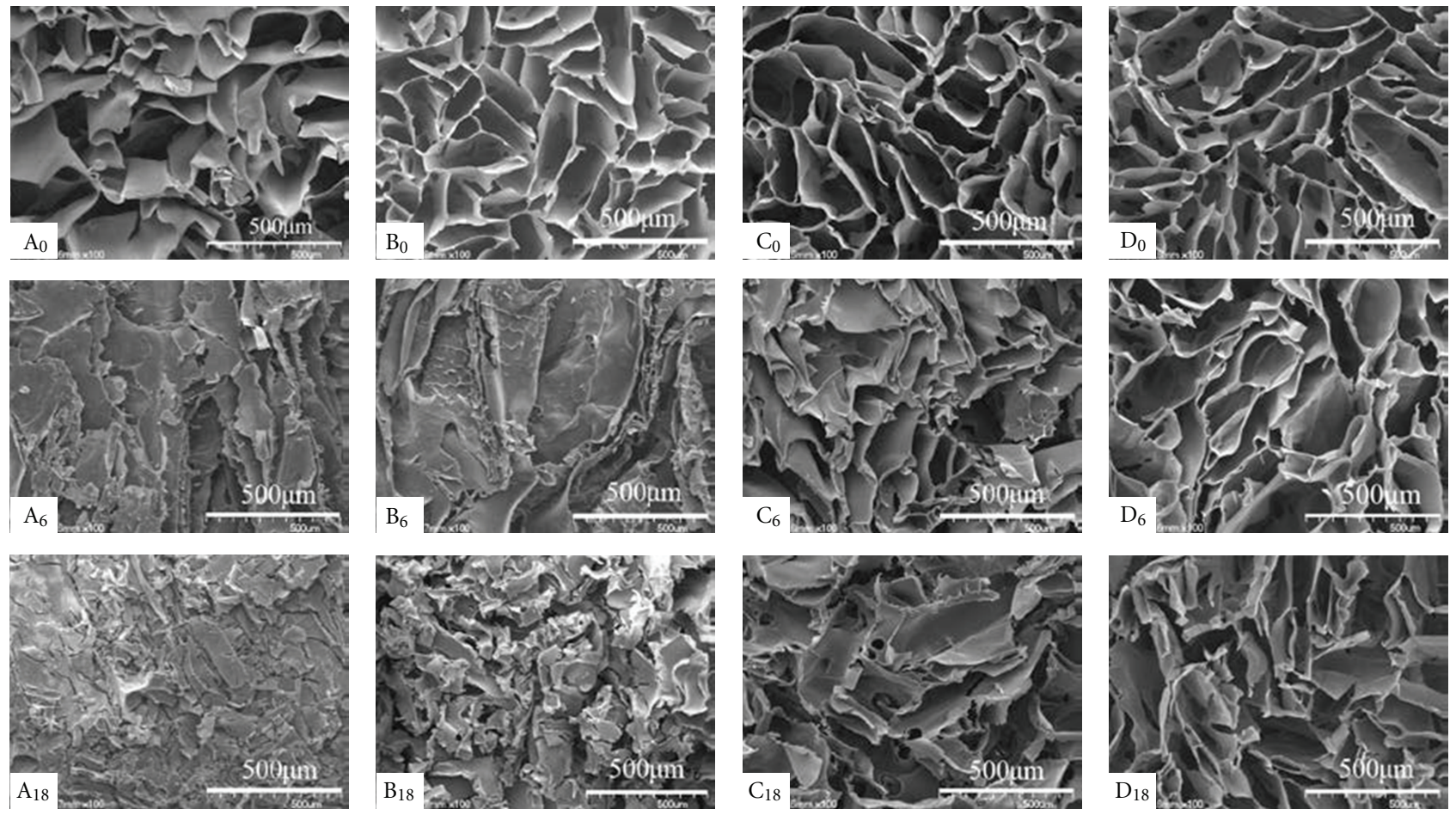

Figure 3: SEM images of four groups of porous silk fibroin scaffolds after degradation for 0 day $\left(A_{0}, B_{0}, C_{0}, D_{0}\right), 6$ days $\left(A_{6}, B_{6}, C_{6}, D_{6}\right), 18$ days $\left(\mathrm{A}_{18}, \mathrm{~B}_{18}, \mathrm{C}_{18}, \mathrm{D}_{18}\right)$ (scale bar $\left.=500 \mu \mathrm{m}\right)$.

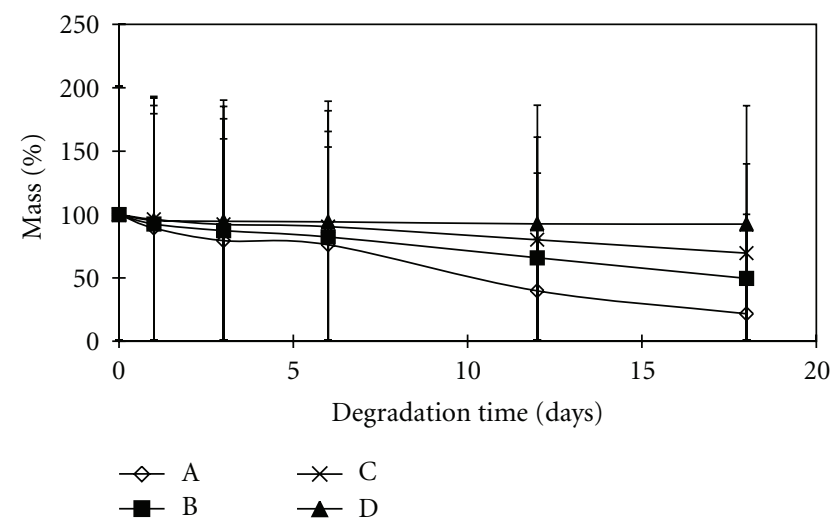

FIGURE 4: Weight change of the four groups of porous silk fibroin scaffolds during enzymatic degradation.

$\beta$-sheet structure in silk fibroin is high and that silk fibroin is not degraded easily by collagenase IA. Water is a very good system for the formation of hydrogen bonds, which are in competition with the hydrogen bonds of the silk fibroin structure. The following sequence of events occurs when the silk fibroin scaffold is immersed in aqueous ethanol. First, water expands the amorphous region of the protein owing to the interruption of hydrogen bonds. Then, ethanol penetrates the swollen region, generating a hydrophobic environment and making the hydrophobic molecule chain segments in the random coils of silk fibroin approach each other more closely and form a crystal nucleus. Finally, a stable $\beta$-sheet structure is formed by growth of the crystal nucleus and rearrangement of hydrogen bonds. The weight of group C fibroin decreased by $30.49 \%$ and the mass loss was between group $\mathrm{B}$ and group $\mathrm{D}$, indicating that the porous silk fibroin scaffold could be degraded by treatment with EDC, but the effect was less than that following treatment with ethanol. Loss of weight of the porous silk fibroin scaffold was greatest, up to $78.34 \%$, in group A. The resistibility of the porous silk fibroin scaffolds to enzyme is significantly different due to the differences of secondary structure of the scaffolds prepared by varying the freezing temperature and by treatment with carbodiimide or ethanol.

\section{Conclusions}

In this study, four groups of porous B. mori silk fibroin scaffolds were prepared with different secondary structure by freeze-drying to investigate the degradation behavior by enzymatic experiments. The high content of $\beta$-sheet structure in the porous scaffold was associated with a slow rate of degradation. Owing to the preference of the protease to attack the random coil region of silk fibroin, the content of random coil was relatively decreased, whereas the content of $\beta$-sheet structure was relatively increased during incubation. It is possible to control the degradation rate of the silk fibroin scaffolds by controlling the $\beta$-sheet structure content for a specific tissue engineering application.

\section{Acknowledgments}

This work was supported by the National Nature Science Foundation of China (30970714), the Nature Science 
Foundation of Jiangsu Province (BK2010252), College Natural Science Research Project of Jiangsu Province (12KJA430003), and the Priority Academic Program Development of Jiangsu Higher Education Institutions.

\section{References}

[1] C. Vepari and D. L. Kaplan, "Silk as a biomaterial," Progress in Polymer Science, vol. 32, no. 8-9, pp. 991-1007, 2007.

[2] S. Inoue, K. Tanaka, F. Arisaka, S. Kimura, K. Ohtomo, and S. Mizuno, "Silk fibroin of Bombyx mori is secreted, assembling a high molecular mass elementary unit consisting of $\mathrm{H}$ chain, L-chain, and P25, with a 6:6:1 molar ratio," Journal of Biological Chemistry, vol. 275, no. 51, pp. 40517-40528, 2000.

[3] T. Arai, G. Freddi, R. Innocenti, and M. Tsukada, "Biodegradation of bombyx mori silk fibroin fibers and films," Journal of Applied Polymer Science, vol. 91, no. 4, pp. 2383-2390, 2004.

[4] R. Valluzzi, S. P. Gido, W. Muller, and D. L. Kaplan, "Orientation of silk III at the air-water interface," International Journal of Biological Macromolecules, vol. 24, no. 2-3, pp. 237-242, 1999.

[5] R. L. Moy, A. Lee, and A. Zalka, "Commonly used suture materials in skin surgery," American Family Physician, vol. 44, no. 6, pp. 2123-2128, 1991.

[6] N. Minoura, S. I. Aiba, Y. Gotoh, M. Tsukada, and Y. Imai, "Attachment and growth of cultured fibroblast cells on silk protein matrices," Journal of Biomedical Materials Research, vol. 29, no. 10, pp. 1215-1221, 1995.

[7] R. E. Unger, K. Peters, M. Wolf, A. Motta, C. Migliaresi, and C. J. Kirkpatrick, "Endothelialization of a non-woven silk fibroin net for use in tissue engineering: growth and gene regulation of human endothelial cells," Biomaterials, vol. 25, no. 21, pp. 5137-5146, 2004.

[8] X. Y. Luan, Y. Wang, X. Duan et al., "Attachment and growth of human bone marrow derived mesenchymal stem cells on regenerated Antheraea pernyi silk fibroin films," Biomedical Materials, vol. 1, no. 4, pp. 181-187, 2006.

[9] Q. Lu, X. Hu, X. Wang et al., "Water-insoluble silk films with silk I structure," Acta Biomaterialia, vol. 6, no. 4, pp. 13801387, 2010.

[10] M. Li, M. Ogiso, and N. Minoura, "Enzymatic degradation behavior of porous silk fibroin sheets," Biomaterials, vol. 24, no. 2, pp. 357-365, 2003.

[11] S. Q. Yan, C. X. Zhao, X. F. Wu, Q. Zhang, and M. Z. Li, "Gelation behavior of Antheraea pernyi silk fibroin," Science China Chemistry, vol. 53, no. 3, pp. 535-541, 2010.

[12] A. Schneider, X. Y. Wang, D. L. Kaplan, J. A. Garlick, and C. Egles, "Biofunctionalized electrospun silk mats as a topical bioactive dressing for accelerated wound healing," Acta Biomaterialia, vol. 5, no. 7, pp. 2570-2578, 2009.

[13] L. Meinel, R. Fajardo, S. Hofmann et al., "Silk implants for the healing of critical size bone defects," Bone, vol. 37, no. 5, pp. 688-698, 2005.

[14] L. Soffer, X. Wang, X. Zhang et al., "Silk-based electrospun tubular scaffolds for tissue-engineered vascular grafts," Journal of Biomaterials Science, vol. 19, no. 5, pp. 653-664, 2008.

[15] L. Uebersax, H. P. Merkle, and L. Meinel, "Insulin-like growth factor I releasing silk fibroin scaffolds induce chondrogenic differentiation of human mesenchymal stem cells," Journal of Controlled Release, vol. 127, no. 1, pp. 12-21, 2008.

[16] A. W. Lloyd, "Interfacial bioengineering to enhance surface biocompatibility," Medical device technology, vol. 13, no. 1, pp. 18-21, 2002.
[17] R. Langer and J. P. Vacanti, “Tissue engineering," Science, vol. 260, no. 5110, pp. 920-926, 1993.

[18] Y. Wang, D. D. Rudym, A. Walsh et al., "In vivo degradation of three-dimensional silk fibroin scaffolds," Biomaterials, vol. 29, no. 24-25, pp. 3415-3428, 2008.

[19] Y. Yang, Y. Zhao, Y. Gu et al., "Degradation behaviors of nerve guidance conduits made up of silk fibroin in vitro and in vivo," Polymer Degradation and Stability, vol. 94, no. 12, pp. 22132220, 2009.

[20] P. Taddei, T. Arai, A. Boschi, P. Monti, M. Tsukada, and G. Freddi, "In vitro study of the proteolytic degradation of $A n$ theraea pernyi silk fibroin," Biomacromolecules, vol. 7, no. 1, pp. 259-267, 2006. 

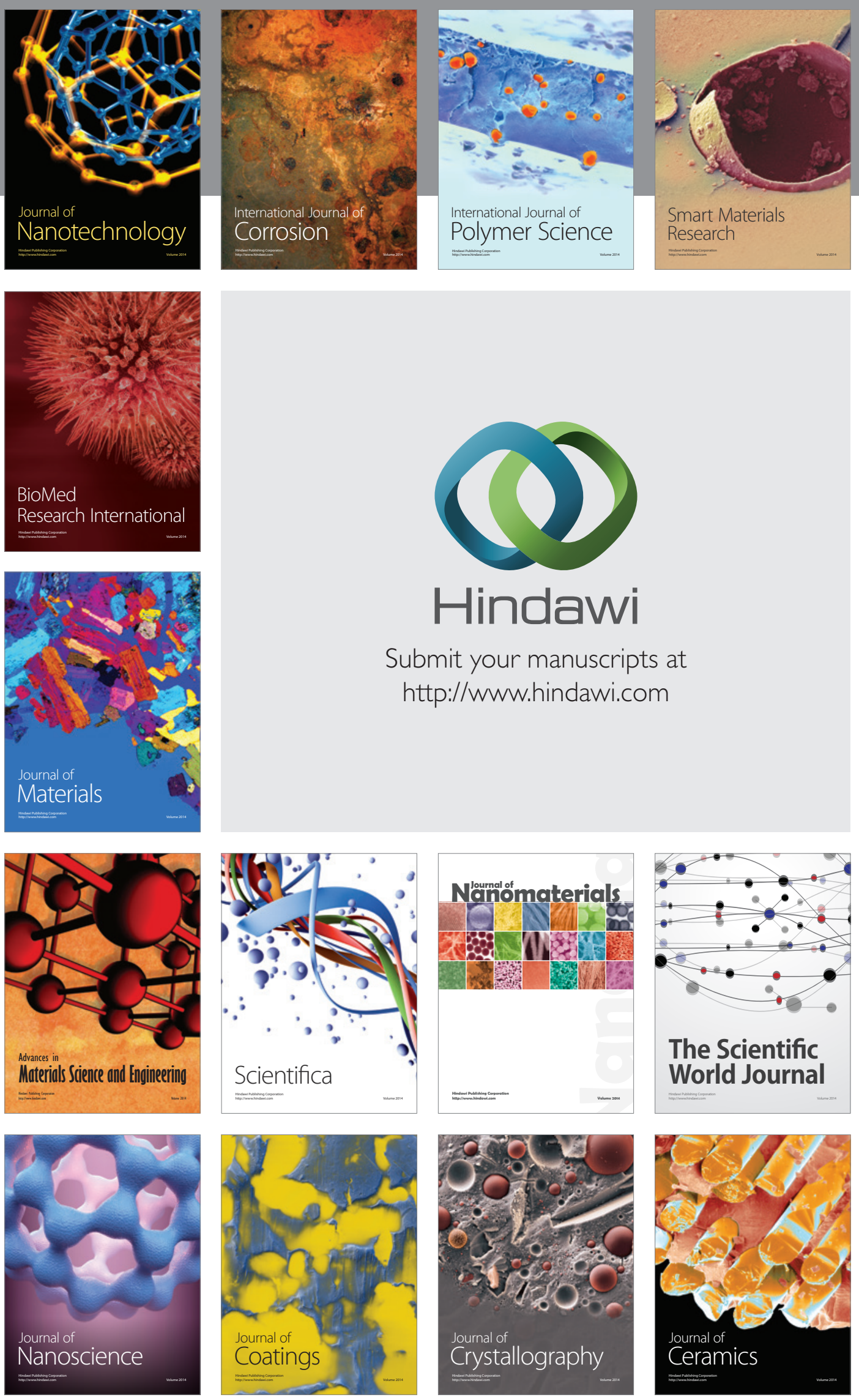

The Scientific World Journal

Submit your manuscripts at

http://www.hindawi.com

\section{World Journal}

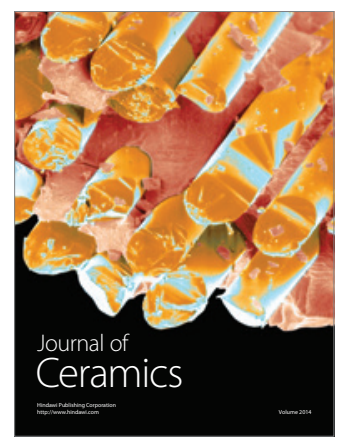

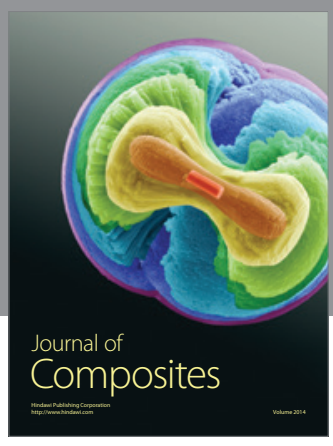
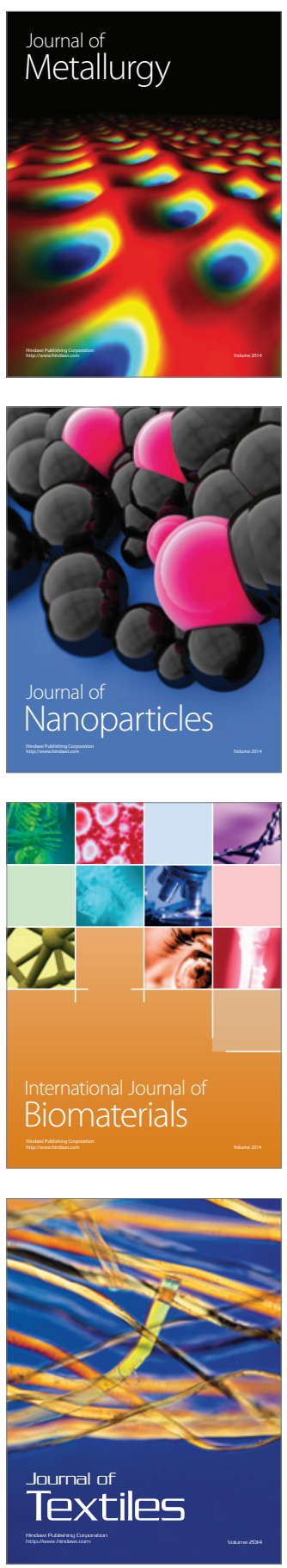